\title{
2-year outcome of juvenile idiopathic arthritis in current daily practice: what can we tell our patients?
}

\author{
Janneke Anink ${ }^{1 *}$, Koert M Dolman ${ }^{2,3}$, Merlijn J van den Berg ${ }^{1,2}$, Mira van Veenendaal ${ }^{1}$, Taco W Kuijpers ${ }^{1}$, \\ Marion AJ van Rossum ${ }^{1,2}$
}

From 18th Pediatric Rheumatology European Society (PReS) Congress

Bruges, Belgium. 14-18 September 2011

\section{Background}

As treatment options in juvenile idiopathic arthritis (JIA) are quickly developing, limited data exist that appear fully applicable for informing our newly diagnosed JIA patients about the expected course of their disease

\section{Aim}

To evaluate disease course and outcome of patients in the first two years after diagnosis JIA when treated according to local standard of clinical care.

\section{Methods}

We performed a retrospective inception cohort study of children with JIA, diagnosed between 2003 and 2007, treated in referral centers in Amsterdam. Disease status was determined for every outpatient clinic visit. Data regarding medication, functional outcome and radiography were recorded.

\section{Results}

149 consecutive newly diagnosed JIA patients were included. Median age at diagnosis was 11.8 years with a median follow up of 33 months. DMARDs were used in $95 \%$ of the patients including methotrexate in $85 \%$, sulfasalazine in $41 \%$ and biologicals in $20 \%$. DMARDs were started within median one month after diagnosis. During follow-up 77\% of patients achieved a total of 244 episodes of inactive disease (ID). ID was reached after median 10 months. After 2 years a median CHAQ score of 0.6 was reported. Radiological joint damage occurred at some point in $12 \%$ of patients: $3 \%$ showed damage at diagnosis and another 9\% developed joint damage within a median of 20 months after their first clinic visit.

\section{Conclusions}

With current management strategies in daily clinical practice, $77 \%$ of newly diagnosed JIA patients achieve a first episode of inactive disease within a median of 10 months. After 2 years, patients report a moderate functional disability and more than $10 \%$ show radiological evidence of joint damage.

\section{Author details}

${ }^{1}$ Pediatric Rheumatology, Emma Children's Hospital, Academic Medical Center, Amsterdam, The Netherlands. ${ }^{2}$ Department Pediatric Rheumatology, Reade location Jan van Breemen,Amsterdam, The Netherlands. ${ }^{3}$ Department of Pediatrics, St Lucas Andreas Hospital, Amsterdam, The Netherlands.

Published: 14 September 2011

doi:10.1186/1546-0096-9-S1-P153

Cite this article as: Anink et al:: 2-year outcome of juvenile idiopathic arthritis in current daily practice: what can we tell our patients? Pediatric Rheumatology 2011 9(Suppl 1):P153.

\footnotetext{
* Correspondence: j.anink@erasmusmc.nl

'Pediatric Rheumatology, Emma Children's Hospital, Academic Medical

Center, Amsterdam, The Netherlands

Full list of author information is available at the end of the article
} 